\title{
PREVALENCE OF HCV INFECTION AMONG HEALTH CARE EMPLOYEE AT AL AZHAR UNIVERSITY HOSPITALS IN CAIRO, EGYPT
} By

MOHAMED DARWISH AHMED ABD ALLA ${ }^{1 *}$, YASSER M. M. EL-DESSOUKY ${ }^{1}$, MOHAMED RASHED ABDEL-HAMID ${ }^{2}$ AND AHMAD NAGY AFIFI ZAIN EL-DEEN ${ }^{1}$ Department of Tropical Medicine ${ }^{1}$, and Department of Clinical Pathology ${ }^{2}$, Faculty of Medicine, El-Hussein University Hospitals, Postal Code 11675, Al-Azhar University, Egypt $\left({ }^{\star}\right.$ Correspondence: darwish0716@azhar.edu.eg, Fax: +2 25123091)

\section{Abstract}

HCV-infection is the main cause of chronic liver disease among Egyptians, the most commonly infected population with HCV genotype 4. Evidences of HCV-transmission that are associated with health-care settings have consistently accumulated over recent years worldwide. Therefore, healthcare workers (HCWs) are the target population of the current study. The study evaluated prevalence of HCV-infection among different sectors of HCWs at Al Azhar University Hospitals. The population $(n=239)$ were divided into four groups. $\mathrm{G} 1(\mathrm{n}=59)$ included healthy controls who were not working at hospitals. Other subjects $(n=180)$ consisted three equal groups $(2,3 \&$ 4) who were working at Al-Azhar University Hospitals. Respectively, workers, nurses and physicians presented group $2,3 \& 4$ ( $\mathrm{n}=60$ each) from different hospital wards. Based upon duration of employment at hospitals, subjects in each of the last three groups were subdivided into 3 subgroups $(n=20$ each). Risk-factors that were thought to have an impact on acquisition of HCVinfection were evaluated. The overall prevalence of HCV infection in study populations was $21.34 \%$ with the highest rate in nurses (38.3\%) and workers (20\%) when compared to controls $(15.3 \%)$ and physicians $(11.7 \%$; $\mathrm{P}<0.05)$. The significantly increased HCV infection in nurses compared to physicians $(\mathrm{P}<0.05)$ was found during all employment periods. Needle stick injury, incidental exposure to blood and body fluid splashes were respectively prominent risk-factors among nurses $(70 \%, 60 \% \& 35 \%)$ and workers $(35 \%, 21.7 \% \& 18.3 \%)$. Nurses and hospital workers had high prevalence of HCV infection. Long duration of nurse employment was associated with increased frequency of needle sticks and subsequently high prevalence of HCVinfection, but not physicians.

Key words: Egypt, Al-Azhar University Hospitals, HCV, HCWs, Risk Factors.

\section{Introduction}

Hepatitis $\mathrm{C}$ virus (HCV) infection is one of the main causes of chronic liver disease worldwide (EASL, 2015). Egypt has been considered one of the most endemic countries for $\mathrm{HCV}$ infection. $\mathrm{HCV}$ prevalence among the 15-59 years age subpopulation was found to be $14.7 \%$ according to The Egyptian Demographic Health Survey (EDHS) (El-Zanaty and Way, 2009). HCV transmission was found to be higher among drug addicts, homosexuals, those who received repeated blood transfusion, unsafe medical or surgical procedures, invasive procedures such as tattooing and acupuncture, also previous history of receiving parenteral anti-Schistosomal treatment (EASL, 2015). The origin of the HCV epidemic in Egypt is believed to be related to mass antischistosomal parenteral treatment campaigns conducted in the 1960s-80s using insufficiently sterilized injection material (Frank $e t$ $a l, 2000)$. Evidence of ongoing transmission of HCV that is associated with health-care settings has consistently accumulated over recent years (Mahmoud et al, 2013).

So, healthcare professionals who work in close contact with patients in Egypt are at increased risk of $\mathrm{HCV}$ infection and other blood borne pathogens (Lee, 2009), with an estimated annual number of 4.9 needle sticks per HCW (Talaat et al, 2003). There were few comprehensive studies on the current prevalence among HCWs in Egypt, with reported $\mathrm{HCV}$ seroprevalence ranging from $7.7 \%$ to $16.6 \%$ (Abdelwahab et al, 2013). $\mathrm{HCV}$ infection may be presented either in acute form tending to be asymptomatic or chronic form. Progression to persistent or chronic infection occurred in about three 
quarters of cases with variable rates of the fibrosis progression (EASL, 2015).

This work aimed to study prevalence of $\mathrm{HCV}$ among health care personals at $\mathrm{Al}$ Azhar University Hospitals for boys in Cairo. The study extended to cover acquisition of HCV infection in association with specific risk factors and employment duration.

\section{Patients and Methods}

The study was approved by the ethical committee at Al Azhar Faculty of Medicine. A cross sectional study that included 239 subjects who were classified into 4 groups. G1: included 59 ages and sex-matched healthy individuals who were not working at hospitals and not known to have a liver disease as control group. One hundred and eighty subjects working at Al-Azhar university hospitals classified into 3 groups. G2: contained 60 medical workers from different hospital wards. G3: included 60 nurses from different hospital wards. G4: consisted of 60 physicians with different specialties. All subjects in last 3 groups were subdivided into 3 subgroups, 20 subjects each, according to the duration of their employment at hospitals as follows: subgroup a: 1 year $+/-6$ months, subgroup b: 3 years+/-6 months and subgroup c: 5 years $+/-6$ months.

Inclusion criteria: persons with mean age (18-60 years) and a written consent was signed by each participant. Exclusion criteria: Patients with known history of liver disease, immunocompromised patients (diabetic patients and patients on corticosteroids), persons with history of receiving parenteral anti-schistosomal treatment, blood transfusion, and intravenous drugs abuse, hemodialysis. The pregnant women and individuals with the history of contact to canal water were also excluded.
Study population were subjected to: 1) Full history taking with special emphasis on $\mathrm{HCV}$ risk factors at hospitals such as: needle stick injury, incidental blood exposure, body fluid splash, as well as, shared nail clipper, tattoo, house hold contacts with $\mathrm{HCV}$ and visiting dental clinics. 2) Thorough clinical examination. 3) Laboratory investigations including: liver biochemical profile: (AST, ALT, ALP, serum albumin, total bilirubin), $\mathrm{HCV}-\mathrm{Ab}$ testing using $3^{\text {rd }}$ generation ELI$\mathrm{SA}$, as well as HCV/RNA by real time PCR to confirm infection in $\mathrm{HCV}-\mathrm{Ab}$ positive cases (with a detection limit of $12 \mathrm{IU} / \mathrm{ml}$ real-time PCR).

Statistical analysis: Data were analysis using SPSS software version 22. $\mathrm{P}$ value was considered significant at $\leq 0.05$.

\section{Results}

The demographic features of studied populations revealed male predominance (149) of the total subjects (259) (62.34\%). Age mean \pm Standard Deviation of the studied subjects was $33.37 \pm 8.77$ years. Table 1 and figure 1 demonstrated both prevalence and distribution rates of $\mathrm{HCV}$ infections among all study groups. Prevalence of $\mathrm{HCV}$ infection was respectively $15.3 \%, 20 \%, 38.3 \%$ and $10 \%$ in controls, workers, nurses, and physicians.

Nurses showed the highest HCV prevalence compared to controls \& physicians $(\mathrm{P}<0.05)$, but not workers $(\mathrm{P}>0.05)$. The distribution of 51 anti-HCV-IgG antibody positive subjects was respectively $17.65 \%$, $23.53 \%, 45.1$, \& 13.73 in controls, workers nurses and physicians respectively. The highest share of HCV infection was in nurses compared to other groups $(\mathrm{P}<0.05)$. The results are shown in tables $(1,2,3 \& 4)$ and figures $(1,2,3 \& 4)$. All subjects presented with positive anti-HCV IgG antibodies had RNA genomic viremia.

Table1. Prevalence of percent positive anti-HCV IgG antibody responses in all study groups

\begin{tabular}{|l|l|l|l|l|}
\hline Anti-HCV IgG antibody results & Controls $(\mathrm{n}=59)$ & Workers $(\mathrm{n}=60)$ & Nurses $(\mathrm{n}=60)$ & Physician $(\mathrm{n}=60)$ \\
\hline Anti-HCV IgG positive: $\mathrm{n}(\%)$ & $9(15.3 \%)$ & $12(20.0 \%)$ & $23(38.3 \%)$ & $7(10.0 \%)$ \\
\hline Anti-HCV IgG negative: $\mathrm{n}(\%)$ & $50(84.7 \%)$ & $48(80 \%)$ & $37(61.7 \%)$ & $53(90 \%)$ \\
\hline P value: comparing the studied 3 groups to controls & 0.041 & 0.005 & 0.556 \\
\hline
\end{tabular}

Nurses and workers had significantly increased frequency of chronic viral hepatitis by serum anti-HCV IgG antibodies compared to controls and physician $(\mathrm{P}<0.05)$, with insignificant difference on comparing controls with physicians $(\mathrm{P}>0.05)$ 
Comparison of means \pm SD of both $\mathrm{IgG}$ antibody optical density (OD) values and viral loads in infected subjects of each group ( 9 controls, 12 workers, 23 nurses, and 7 physicians) with each other did not show any significant changes $(p>0.05)$. On the other hand, figure 2 illustrated the comparison of ELISA OD reading of all individual subjects in different study groups. The mean ELISA OD reading of nurses was significantly higher compared to the other study groups $(\mathrm{P}<0.05)$.

Table 2: Anti-HCV IgG antibody ELISA OD reading \& HCV SRT-PCR subjects presented with positive serology in all groups

\begin{tabular}{|l|c|c|}
\hline $\begin{array}{l}\text { Groups (\# of anti-HCV IgG Abs positive } \\
\text { subjects in each group) }\end{array}$ & $\begin{array}{c}\text { ELISA OD Reading } \\
\text { Mean } \pm \text { SD }\end{array}$ & $\begin{array}{c}\text { HCV-RNA PCR } \\
\text { Mean } \pm \text { SD }\end{array}$ \\
\hline Controls ( $=9$ ) & $0.6002 \pm 0.1935$ & $1,240,263 \pm 925221.01020$ \\
\hline Workers (n=12) & $0.5718 \pm 0.1638$ & $658302.681 \pm 658302.6810$ \\
\hline Nurses ( $\mathrm{n}=23)$ & $0.6061 \pm 0.1796$ & $1,409,585 \pm 911813.20290$ \\
\hline Physicians (n=7) & $0.4651 \pm 0.1212$ & $900,074 \pm 741219.3204000$ \\
\hline P - Values: Controls VS Work & 0.719184933 & 0.545987752 \\
Controls VS Nurse & 0.935233822 & 0.646210224 \\
Controls VS Physicians & 0.129478107 & 0.43811877 \\
Worker VS Nurses & 0.583762976 & 0.884782555 \\
Worker Vs physicians & 0.110124901 & 0.110124901 \\
Nurses VS physicians & 0.063093523 & 0.180428469 \\
\hline
\end{tabular}

$O D=$ Optical density, SRT-PCR $=$ Serum real time-polymerase chain reaction. Abs=Antibodies

All positive HCV IgG Ab cases in the study subjects had detectable HCV RNA by real time PCR. Both serum anti-HCV IgG antibodies and SRT-PCR loads had insignificant changes on comparing all groups with each other.

The needle stick injury, incidental blood exposure, and body fluid splash occurred more often in workers, nurses, and doctors compared to controls $(\mathrm{P}<0.05)$. Nurses had significantly higher frequency of needle stick injury, incidental blood exposure, body fluid splash, and shared nail clipper compared to workers $(\mathrm{P}<0.05)$. Visiting dental clinic was performed more often by nurses compared to controls and workers $(\mathrm{p}<0.05)$. Needle stick injury and shared nail clipper were less frequent in physicians compared to nurses $(\mathrm{p}<0.05)$. No significant changes were observed among groups as to tattoo and house hold contact with HCV infection $(\mathrm{P}>0.05)$. The most prominent HCV infec-

Table 3: Frequencies' of exposure to risk factors in all groups.

\begin{tabular}{|l|c|c|c|c|c|c|c|}
\hline Groups & $\begin{array}{c}\text { Needle } \\
\text { stick injury } \\
\text { No (\%) }\end{array}$ & $\begin{array}{c}\text { Incidental } \\
\text { blood expos- } \\
\text { ure No (\%) }\end{array}$ & $\begin{array}{c}\text { Body fluid } \\
\text { splash } \\
\text { No }(\%)\end{array}$ & $\begin{array}{c}\text { Shared nail } \\
\text { clipper } \\
\text { No (\%) }\end{array}$ & $\begin{array}{c}\text { Tattoo } \\
\text { No (\%) }\end{array}$ & $\begin{array}{c}\text { House hold } \\
\text { contact No } \\
(\%)\end{array}$ & $\begin{array}{c}\text { Visiting den- } \\
\text { tal clinic } \\
\text { No (\%) }\end{array}$ \\
\hline Control & 3 & 4 & 0 & 19 & 8 & 23 & 15 \\
$\mathrm{n}=59$ & $(5.1 \%)$ & $(6.7 \%)$ & $(0 \%)$ & $(32.3 \%)$ & $(13.6 \%)$ & $(39 \%)$ & $(25.4 \%)$ \\
\hline Workers & $21^{\mathrm{a}}$ & $13^{\mathrm{a}}$ & $11^{\mathrm{a}}$ & 26 & 2 & 28 & 14 \\
$\mathrm{n}=60$ & $(35 \%)$ & $(21.7 \%)$ & $(18.3 \%)$ & $(43.3 \%)$ & $(3.3 \%)$ & $(46.7 \%)$ & $(23.3 \%)$ \\
\hline Nurses & $42^{\mathrm{a}, \mathrm{b}}$ & $36^{\mathrm{a}, \mathrm{b}}$ & $21^{\mathrm{a}, \mathrm{b}}$ & $12^{\mathrm{b}}$ & 5 & 24 & 25 \\
$\mathrm{n}=60$ & $(70 \%)$ & $(60 \%)$ & $(35 \%)$ & $(20 \%)$ & $(8.3 \%)$ & $(40 \%)$ & $(41.7 \%)^{\mathrm{a}, \mathrm{b}}$ \\
\hline Physicians & $30^{\mathrm{a}, \mathrm{c}}$ & $28^{\mathrm{a}, \mathrm{b}}$ & $13^{\mathrm{a}}$ & $0^{\mathrm{a}, \mathrm{b}, \mathrm{c}}$ & 0 & 19 & 20 \\
$\mathrm{~N}=60$ & $(50 \%)$ & $(46.7 \%)$ & $(21.7 \%)$ & $(0 \%)$ & $(0 \%)$ & $(31.7 \%)$ & $(33.3 \%)$ \\
\hline
\end{tabular}

a: p-value $<0.05$ compared to control group. b: p-value $<0.05$ in comparison with workers group. c: p-value $<$ 0.05 upon comparing to nurses group. tion risk factors in controls were the house hold contact with HCV infection and shared nail clipper $(\mathrm{P}<0.05)$; the same finding was reported in workers, despite close to significant association with needle stick injury $(\mathrm{P}=$ 0.07). The two main risk factors (needle stick injury and incidental blood exposure) were significantly present in nurses $(\mathrm{P}<$ $0.05)$ compared to the rest of risk factors. Needle stick injury, incidental blood exposure, house hold contacts with HCV, body fluid splash, and visiting dental clinic were equally preset in physicians, and they were significantly higher than shared nail clipper and tattoo $(\mathrm{P}<0.05)$. 
Studying the relationship of employment duration with probability of $\mathrm{HCV}$ infections in all groups was demonstrated in table 4 . Within each group, no significant changes in frequency of $\mathrm{HCV}$ infection were reported in the studied subgroups upon comparison with each other $(\mathrm{P}>0.05)$. On the other hand, figure 4 illustrated the correlation of $\mathrm{HCV}$ infection with duration of employment in each subgroup category of the studied three groups. Nurses had significantly increased HCV infection rates compared to physicians $(\mathrm{P}<0.05)$ after working for at least 3 years, otherwise no significant changes were noted on comparing the three groups with each other at the rest of the three periods $(\mathrm{P}>0.05)$.

Table 4: Prevalence of HCV infection in study subgroups by SRT-PCR

\begin{tabular}{|l|c|c|c|}
\hline Subgroups & Physicians $(7 / 60=10.0 \%)$ & Workers $(12 / 60=20.0 \%)$ & Nurses $(23 / 60=38.3 \%)$ \\
\hline Subgroup (a) $(\mathrm{n}=20)$ & $2(10 \%)$ & $2(10 \%)$ & $5(25 \%)$ \\
\hline Subgroup (b) $(\mathrm{n}=20)$ & $2(10 \%)$ & $4(20 \%)$ & $8(40 \%)$ \\
\hline Subgroup (c) $(\mathrm{n}=20)$ & $3(15 \%)$ & $6(30 \%)$ & $10(50 \%)$ \\
\hline P Value a vs. b & 1.00 & 0.6141 & 0.5006 \\
a vs. c & 1.00 & 0.2351 & 0.1910 \\
b vs. c & 1.00 & 0.7164 & 0.7511 \\
\hline
\end{tabular}

Duration of employment didn't not have any significant changes on HCV infection rates ( $>>0.05)$ within each group. Subgroup (a): duration of work at the hospital 1 year \pm 6 months. Subgroup (b): duration of work at the hospital 3 years \pm 6 months. Subgroup (c): duration of work at the hospital 5 years \pm 6 months.

Correlation of risk factors frequencies in subgroups with employment durations showed the following: 1) no significant changes in all risk factors prevalence in worker's subgroups when compared to each other $(\mathrm{P}>0.05)$ 2) Needle stick injury had a higher prevalence in nurse's subgroup $3 \mathrm{c}$ (95\%) in comparison to both subgroups $3 \mathrm{a}$ $(45 \%)$ \& 3b $(70 \%)(\mathrm{P}<0.05) 3)$ Incidental blood exposure and body fluid splash were increased in subgroup $3 \mathrm{~b}$ (80\% \& 55\%), with insignificant decrease in subgroup $3 \mathrm{c}$ (45\% \& 20\%) (P>0.05) 4) Needle stick injury was reported by $65 \%$ of physicians in subgroup $4 \mathrm{~b}$ and $30 \%$ in subgroup $4 \mathrm{a}$ $(p<0.05)$ associated with insignificant decline in subgroup $4 \mathrm{c}(55 \% ; \mathrm{P}>0.05)$.

\section{Discussion}

The current study addresses prevalence of $\mathrm{HCV}$ infection among the substantial risk groups of hospital employees. Highest prevalence was recognized among nurses compared to physicians, and workers. The main source of infection in nurses was found to be related to needle stick injury, incidental blood exposure, and body fluid splash. Prolonged exposure of nurses to the mentioned risk factors was associated with increased prevalence of $\mathrm{HCV}$ infection compared to other hospital employees after three years of employment. This was proved particular among nursing staff by Abdel-Motagaly et al. (2017) who reported that nurses thought a little needle pricking might be a carrier of one of many transferred diseases. This would be explained by the fact that HCV infection starts early during the first year of employment. For this reason, we strongly recommend that nurses should receive early training programs on practices that is related to ID prevention and control.

The hepatitis $\mathrm{C}$ virus (HCV) infection acquired its major risk from being unnoticed in majority of cases, variability in the clinical presentations, and its late burden on liver e.g. extensive fibrosis and cirrhosis with or without hepatocellular carcinoma. Despite the number of chronically infected persons worldwide is estimated to be about 160 million, only a fraction of them are aware of their infection. Despite the mass screening that currently happening in Egypt, the implementation of extended criteria for routine screening for HCV was a controversial subject among different stakeholders (EASL, 2015).

The present study tried to uncover the questionable facts behind the increased risk of HCV infection among hospital personnel who live in one of the most endemic areas 
for HCV infection worldwide (Gorodin et al, 2013). The targeted populations of our study included Al Azhar University Hospital employees who are working in patient's wards. The prevalence of HCV infection as well as risk factors for $\mathrm{HCV}$ transmission in each group were studied to find out the most important risk factors for the $\mathrm{HCV}$ infection among health care personnel. Controlling these risk factors will lead to correction and improvement of the quality of health education among medical workers.

The present study reported high prevalence of HCV infections among nurses and workers more than normal population because of occupational exposure to needle stick injury, body fluids and blood of HCV infected patients, and they have long standing contact with HCV patients in hospitals. Goniewicz et al. (2012) reported the same conclusions. Justification of the increased HCV prevalence among nurse would be related to the fact that globally, more than 35 million health care workers face the risk of sustaining a percutaneous injury with a contaminated sharp object every year. The fact that injuries of medical and health staff from sharp or pointed objects are among the most frequently reported occupational accidents in healthcare workers was added by Manzoor et al. (2010). The multiplicity of risk factors related to their work at hospital that added to other risk factors outside the hospital might play a key role in the increased infection transmission as reported by Westermann et al. (2015).

The current study found that all positive anti-HCV Ab IgG antibody cases had detectable HCV RNA genomic particles by real time PCR. This finding indicated that none of the HCV infected cases has a chance to spontaneously clear the $\mathrm{HCV}$ infections as used to be normally happening in 15 to $25 \%$. This would be explained by continuously repeated exposure to risk factors that lead to reinfections. Unfortunately, this explanation might not be applicable to controls that can be excused by the small number of
anti-HCV IgG antibody positive subjects. However, control subjects and workers in current study were found to share nail clipper and to have a house hold contact with HCV infection more than any of the studied groups. On the other hand, continuous needle stick injury and incidental blood exposure explained the high prevalence of $\mathrm{HCV}$ infection among nurses that has a reasonable probability of RNA-genomic seroconversion (Manzoor et al, 2010; Westermann et al, 2015). The present data agreed with other developing countries e.g. Saudi Arabia and Pakistan (Mahfouz et al, 2009; Manzoor et al, 2010; Okasha et al, 2015). In developed countries like USA and UK, incidence of needle stick injury in nurses is respectively $16.3 \%$ \& $48 \%$ (Goniewicz et al, 2012) that could be prevented by using the safety devices and the health education programs (Westermann et al, 2015).

The present study reported incidental blood exposure in $60 \%$ of nurses, $46.7 \%$ of physicians and $21.7 \%$ of medical workers, while body fluid splash was identified in $35 \%$ of nurses, $21.7 \%$ of physicians and $18.3 \%$ of medical workers. Exposure to $\mathrm{HCV}$ infected body fluid as well as needle stick injury play a key role in jeopardizing occupational health and safety that face healthcare professionals globally and are associated with high prevalence of infection among HCWs (Deisenhammer et al, 2006; Mbaisi et al, 2013; Markovic-Denica et al, 2015). Other risk factors like dental clinic visit and shared nail clipper were also reported in the current work, which might have a role in HCV transmission (Perdelli et al, 2008; Cavalhiero et al, 2009).

The duration of employment was found in our work to have a positive impact on liability to $\mathrm{HCV}$ infection in nurses and was attributed to increased exposure to needle stick injury and infected fluid splash. Despite needle stick injuries (NSIs) were more frequent in inexperienced personnel, current findings on the incidence of NSI in the health service show that nursing and medical 
personnel are the most frequently affected professional group (Goniewicz et al, 2012).

It should be remembered that the risk of seroconversion after an injury depends on factors including the type of injury (deep cuts or pricks), the quantity of infectious material transferred, the virus load in the index patient and possibly genetic factors in the injured person (Westermann et al, 2015). Our data failed to establish the relationship between the duration of employment with probability of increased HCV circulation among members of other groups as well as their subgroups.

It was highly recommended by authors of current study to address frequency of occult $\mathrm{HCV}$ (OCI) in all groups by screening for the intracellular genomic RNA strands (Abd Alla et al, 2017), as it plays a role in prevalence estimation as well as viral management (Abd Alla and El Awady 2017).

\section{Conclusion}

The current study showed an increase in the prevalence of $\mathrm{HCV}$ infection in HCWs (medical workers and nurses) compared to controls ( $p$-value<0.05). The longer work duration of health care workers at hospitals was not associated with higher prevalence of $\mathrm{HCV}$ infection ( $\mathrm{p}$-value $<0.05$ ).

The needle stick injury was the most important occupational health hazard in nurses and workers with alarmingly high rates and continues to be the major threat to the health of HCWs.

It was recommended to use safe practices for working with blood to help minimizing occupational exposure. Strict adherence to universal precautions is essential to prevent iatrogenic transmission of the infection is highly advisable. The screening of the nurses after needle stick injury and promotion of safety measures against it should be encouraged.

\section{Acknowledgments}

The authors would like to express their thank to the authorities of Faculty of Medicine at Al-Azhar University, Cairo, Egypt for the kind financial support of this work.

\section{References}

Abd Alla, MDA, El Awady, MK, 2017: Hepatitis $\mathrm{C}$ virus RNA strands detection in peripheral blood mononuclear cells legitimizes virus eradication in negative serum PCR naïve and posttreatment patients. J. Clin. Transl. Hepatol. 5, 1: 1-8

Abd Alla, MDA, Elibiary, SA, Wu, G, El Awady, MK, 2017: Occult HCV Infections (OCIs) Diagnosis in Cirrhotic and Non-Cirrhotic Naïve Patients by Intra-PBMCs Nested Viral RNA PCR. J. Clin. Transl. Hepatol (accepted: manuscript No. JCTH-D-17-00034R1).

Abdel-Motagaly, AME, Ibrahim, AMA, Morsy, TA, 2017: An intervention program on the blood protozoa acquired by needle stick injury and infection control. J. Egypt. Soc. Parasitol. 47, 2:309-22

Abdelwahab, SF, Hashem, M, Galal, I, Sobhy, M, Abdel-Ghaffar TS, et al, 2013: Incidence of hepatitis $\mathrm{C}$ virus infection among Egyptian healthcare workers at high risk of infection. J. Clin. Virol. 57, 1:24-8.

Cavalheiro, Nde P, De La, Rosa A, Elagin, S, Tengan, FM, Araújo, ES, et al, 2009: Hepatitis C: sexual or intrafamilial transmission? Epidemiological and phylogenetic analysis of hepatitis $\mathrm{C}$ virus in 24 infected couples. Rev. Soc. Bras. Med. Trop. 42, 3:239-44.

Deisenhammer, S, Radon, K, Nowak, D, Reichert, J, 2006: Needle stick injuries during medical training. J. Hosp. Infect. 63:263-7.

EASL, 2015: EASL Recommendations on treatment of hepatitis C 2015. J. Hepatology.

El-Zanaty, F, Way, A, 2009: Egypt Demographic and Health Survey 2008. Cairo: Ministry of Health, El-Zanaty and Associates, and Macro International.

Frank, C, Mohamed, MK, Strickland, GT, Lavanchy, D, Arthur, RR, et al, 2000: The role of parenteral antischistosomal therapy in the spread of hepatitis C virus in Egypt. Lancet 355: 887-91.

Goniewicz, M, Wloszczak-Szubzda, A, Niemcewicz, M, Witt, M, Marciniak-Niemcewicz, A, et al, 2012: Injuries caused by sharp instruments among healthcare workers--international and Po-lish perspectives. Ann. Agric. Environ. Med. 19: 523-7.

Gorodin, S, Unal, S, Wang, Y, Mikhaylov, M I, Bigbulatova, L, et al, 2013: New Tools in HCV Diagnosis, in Light of the Enhanced Awareness and the New Drugs for Treatment: 
SMAR Tube and Stimmunology. Sci. World. J. 389780, 12 pages. http://dx.doi.org/10.1155/ 389780.

Lee, R, 2009: Occupational transmission of blood borne diseases to healthcare workers in developing countries: meeting the challenges. J. Hosp. Infect. 72, 4:285-91.

Mahfouz, AA, Abdelmoneim, I, Khan, MY, Daffalla, AA, Diab, MM, et al, 2009: Injection safety at primary health care level in southwestern Saudi Arabia. East. Mediter. Hlth. J. 15: 443-50.

Manzoor, I, Daud, S, Hashmi, NR, Sardar, H, Babar, MS, et al, 2010: Needle stick injuries in nurses at a tertiary health care facility. J. Ayub Med. Coll. Abbottabad. 22, 3:174-8.

Markovic-Denica, L, Maksimovic, N, Marusic, V, Vucicevic, J, Ostric, I, et al, 2015: Occupational Exposure to Blood and Body Fluids among Health-Care Workers in Serbia. Med. Princ. Pract. 24:36-41.

Mbaisi, EM, Nganga, Z, Wanzala, P, Omolo, J, 2013: Prevalence and factors associated with percutaneous injuries and splash exposures among health-care workers in a provincial hospital, Kenya. Pan Afri. Med. J. 14:104-8.
Mohamoud, YA, Mumtaz, GR, Riome, S, Miller, D, Abu-Raddad, LJ, 2013: The epidemiology of hepatitis C virus in Egypt: a systematic review and data synthesis. Infect Dis. 13: 28892.

Okasha, O, Munier, A, Delarocque-Astagneau, E, El Houssinie, M, Rafik, M, et al, 2015: Hepatitis $\mathrm{C}$ virus infection and risk factors in health-ca-re workers at Ain Shams University Hospitals, Cairo, Egypt. East. Medite. Hlth. J. 21, 3:199-212.

Perdelli, F, Spagnolo, AM, Cristina, ML, Sartini, M, Malcontenti, R, et al, 2008: Evaluation of co-ntamination by blood aerosols produced during various healthcare procedures. J. Hosp. Infect. 70:174-9.

Talaat, M, Kandeel, A, El-shobary, W, Bodenschatz, C, Khairy, I, et al, 2003: Occupational exposure to needle stick injuries and hepatitis B vaccination coverage among health care workers in Egypt. Am. J. Infect. Control 31, 8:469-74.

Westermann, C, Peters, C, Lisiak, B, Lamberti, M, Nienhaus, A, 2015: The prevalence of hepatitis $\mathrm{C}$ among healthcare workers: a systematic review and meta-analysis. Occup. Environ. Med. 72: 880-8.

\section{Explanation of figures}

Fig. 1: Percent distribution of anti-HCV IgG antibody positive subjects in study groups $(n=51)$. Nurses had a significantly higher share of $\mathrm{HCV}$ infection compared to controls, workers and physicians $(\mathrm{P}<0.05)$ with insignificant changes in infection rates on comparing workers, physicians and controls with each other $(\mathrm{P}>0.05)$.

Fig. 2: Anti-HCV IgG antibody responses in all study groups. Anti-HCV IgG antibodies were significantly higher in nurses compared to controls, workers and physicians $(\mathrm{P}<0.05)$. Same changes were significantly increased in workers compared to physicians $(\mathrm{P}=0.045)$. Dotted line $=$ Cutoff point of ELISA Optical Density $(\mathrm{OD})$ Reading. Dashed lines = Mean ELISA OD reading.

Fig. 3: Frequency of risk factors in each of four study groups. Most prominent HCV infection risk factors in controls (A) and workers (B) were the house hold contact with HCV infection (6) and shared nail clipper (4) (P < 0.05 compared to other risk factors). Needle stick injury (1) and incidental blood exposure (2) significantly present in nurses (C) (P < 0.05). Needle stick injury (1), incidental blood exposure (2), House hold contact with HCV (6), body fluid splash (3), and visiting dental clinic (7) equally observed in physicians (D), but they are significantly higher than Shared nail clipper (4) and tattoo (5) $(\mathrm{P}<0.05)$. $1=$ Needle stick injury. $2=$ incidental blood exposure. 3 = Body fluid splash. $4=$ Shared nail clipper. $5=$ Tattoo. $6=$ House hold contact with HCV. 7 = Visiting dental clinic. 

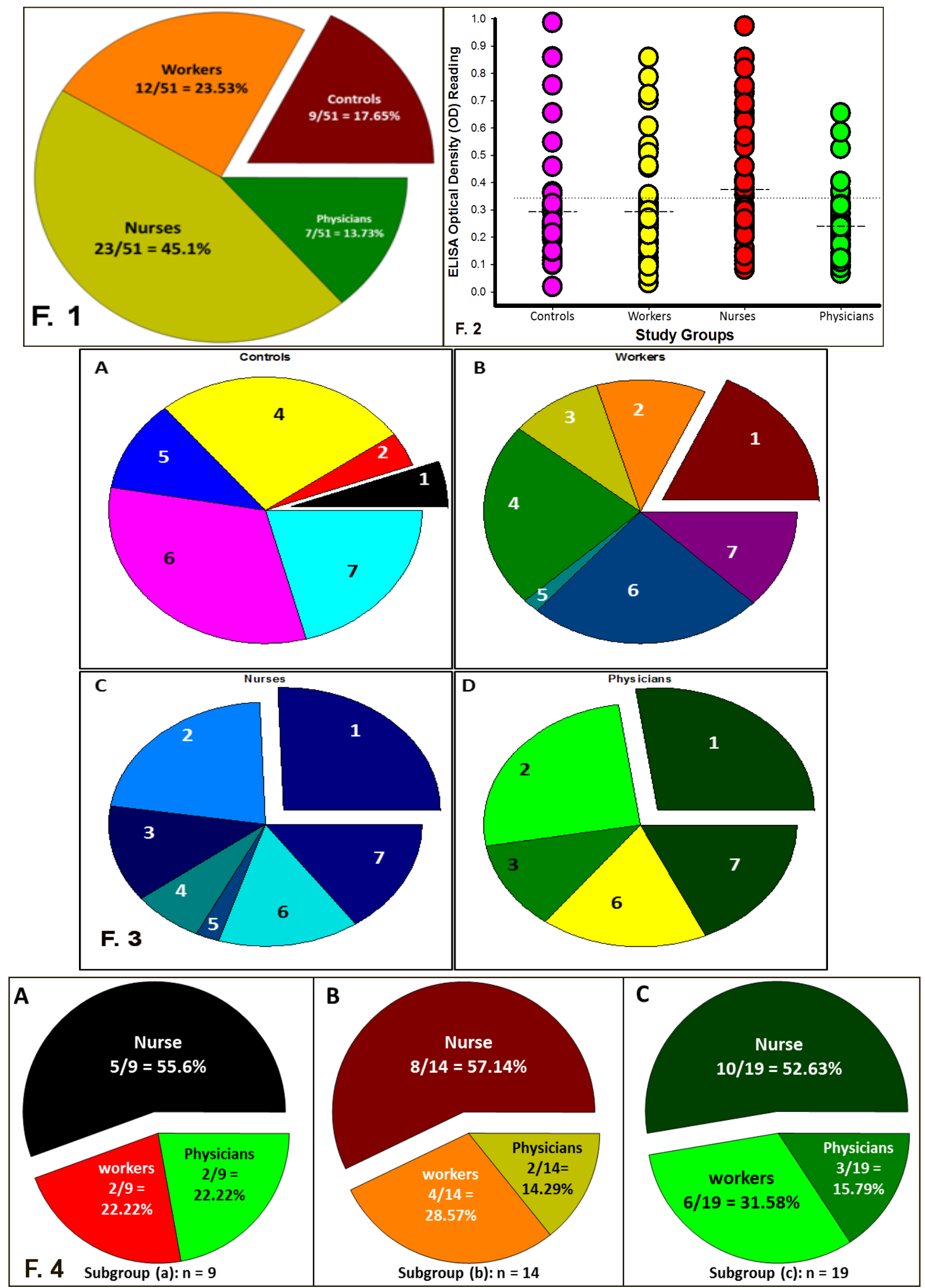